\section{俩 Heighten Science \\ P U B L I C I T I O N S Corporation ISSN 2637-3793}

\title{
Catamenial pneumothorax: Presentation of an uncommon Pathology
}

\author{
Rui Haddad ${ }^{1 *}$, Caterin Arévalo ${ }^{2}$ and David Nigri ${ }^{3}$ \\ ${ }^{1}$ Thoracic Surgeon, Department of Thoracic Surgery, Hospital Samaritano, Rio de Janeiro, Brazil \\ ${ }^{2}$ Resident of General Surgery, Universidad del Sinú, Cartagena de Indias, Colombia \\ ${ }^{3}$ Pneumologist, Department of Pulmonology and Bronchoscopy, Hospital Samaritano, Rio de \\ Janeiro, Brazil
}

*Address for Correspondence: Rui Haddad, MD, Department of Thoracic Surgery Rua Barão de Lucena 48-Room 3 Botafogo CEP: 22260-020 Rio-RJ-Brazil, Email: ruihaddad@me.com

Submitted: 14 December 2017

Approved: 19 Desember 2017

Published: 20 December 2017

Copyright: @ 2017 Haddad R, et al. This is an open access article distributed under the Creative Commons Attribution License, which permits unrestricted use, distribution, and reproduction in any medium, provided the original work is properly cited

Keywords: Catamenial pneumothorax Endometriosis; Thoracic endometriosis syndrome; Pneumothorax

Check for updates

\section{Abstract}

The catamenial pneumothorax is defined as the accumulation of air in the pleural cavity that appears in women infrequently and spontaneously with various clinical presentations. Actually, it is considered as an extremely rare entity with few cases described in the literature, that is the reason why the etiology is still discussed. However, a strong association with thoracic endometriosis syndrome has been found. We want to emphasize how the importance of conducting a diagnosis and having a timely management would improve the quality of life of the patient and give a better prognosis of the disease.

Thus, a case report of a 38-year-old female patient who was receiving hormone therapy as a treatment for abdominal endometriosis and repetitive pneumothorax was presented. In the video-assisted thoracoscopy we saw diaphragmatic lesions and pneumothorax during the perioperative and postoperative period. Emphasize the importance of a detailed inspection of each intrathoracic organ during the surgical procedure, we also showed how the intraoperative pleurodesis, the placement of a mesh on the diaphragm and the continuity of the hormonal treatment, seems to be an effective therapy to prevent recurrences and have a better control of the disease.

\section{Introduction}

The first description of the recurrent catamenial pneumothorax is performed by Maurer et al. [1], some cases have been described in the world literature, which has allowed to improve their diagnosis, however, there is still no consensus on the best standard therapeutic attitude of the disease [2]. Endometriosis has been characterized as one of the most important and predisposing factors in the development of this pathology. We describe the history of a woman with recurrent pneumothorax caused by pelvic endometriosis with thoracic implants and discuss the different mechanisms and current therapies for the management of the main complications of this pathology.

\section{Clinical case}

A 38-year-old, non-smoker, female, presented with clinical pictures of chest pain and dyspnea of 30 days of evolution, with a history of multiple episodes of right pneumothorax. Carrier of pelvic endometriosis in hormonal therapy and antecedent of bladder and left ureteral obstruction, improved with double J catheter placement. It was evaluated by our thoracic surgery department, who initially gave us expectant management of pneumothorax. Given pre- and postoperative recurrent respiratory symptoms, she was submitted to drainage and prosthesis placement by assisted videoassisted thoracoscopy, evidencing extensive pleural endometriosis with multiple diaphragmatic pores (Figure 1), in tendon centers, pleural micronodules, and scars at the apex. Due to the findings, apicoectomy of the right upper lobe, diaphragmatic 
plasty with polyethynylglycol mesh placement covering the diaphragm defects (Figure 2), pleural biopsy, pleural drainage with a pig-tail catheter, and pleurodesis with $2 \%$ iodopovidone were performed. The pathology report confirmed endometriosis throughout the specimen withdrawn. She tolerated the procedure well and continued with hormonal therapy. However, during the postoperative period it presents persistent air leakage through the drain. Due to the persistence of fistula, she is hospitalized for new examinations and conduct determination. Patient without respiratory symptoms or pain, normal pulmonary auscultation, with studies of normal radiological images and self-limitation of the fistula. She is discharged with a CT scan at 1 month, which is normal and without recurrence of symptoms.

Due to the persistence of pelvic symptoms, 5 months after thoracoscopic surgery, the patient underwent an ultra-low anterior rectal resection with mechanical anastomosis through a highly complex robotic surgery (Figure 3), after placement of a chest tube, which was removed on the third day without problems in the postoperative period. Therefore, it is demonstrated the importance of the interdisciplinary management of the patient by the whole group of general surgeons, thoracic, urologists, proctologists and gynecologists.

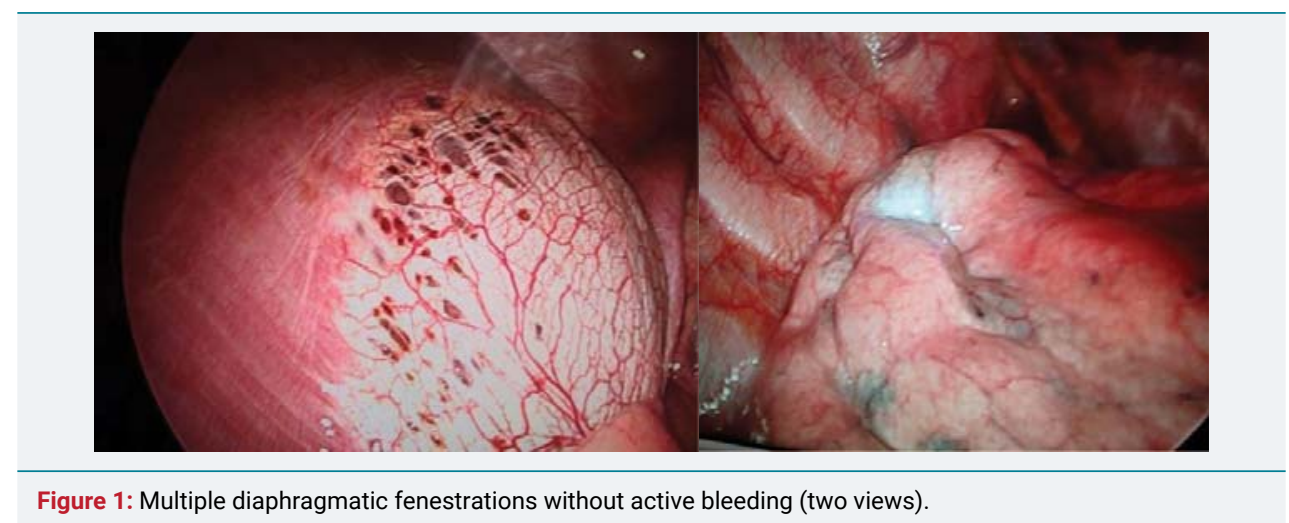

Figure 1: Multiple diaphragmatic fenestrations without active bleeding (two views).

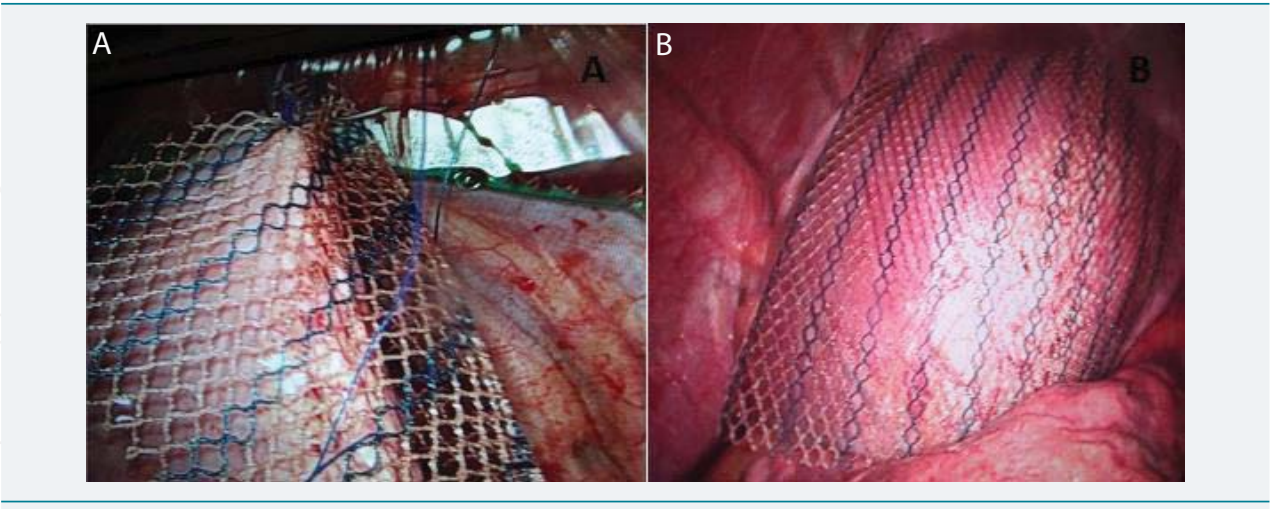

Figure 2: Assisted Video-assisted thoracoscopy with: A. Placement of mesh in right hemidiaphragm. B. Positioning of the material.

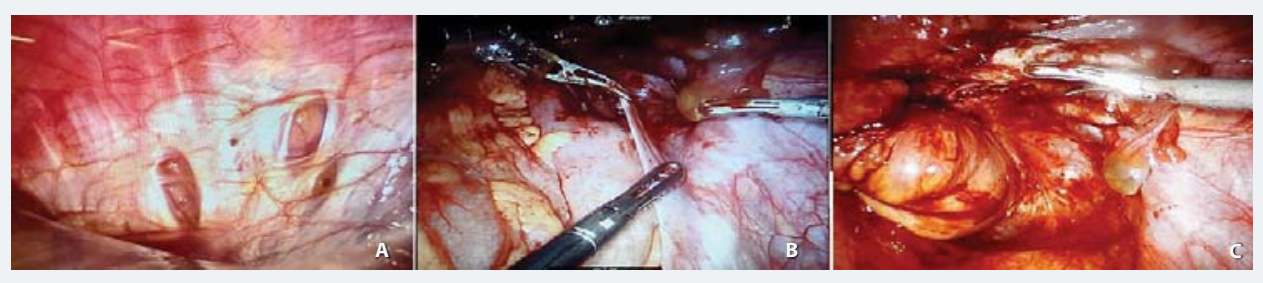

Figure 3: A. Review of Diaphragm with intra-abdominal chamber lens. Decreased injuries. B and C. Initiation of adhesion release and dissection of intra-pelvic tissue planes for subsequent ultra-low anterior rectal resection. Evidence of residual endometriosis in multiple intraabdominal organs. 


\section{Discussion}

The appearance of endometriosis in women is in the reproductive age. The incidence of catamenial pneumothorax associated with it is low, 5-15\% [3-5], however, in our case the initial age of occurrence of the disease, coincided with that reported (older than 40 years) in previous studies [6].

Also, the rate of complicated endometriosis in this type of pneumothorax varies from $25 \%$ to $60 \%$, requiring inspection of the pelvic cavity by laparoscopy or laparotomy, in most cases [7].

Endometriosis that involves the chest cavity or lungs usually presents with catamenial symptoms of pneumothorax, hemothorax or hemoptysis. Karpel et al. [2], reviewed 84 cases of pulmonary endometriosis, revealing the dominance of right-sided pneumothorax in a minority of patients who had concurrent pelvic endometriosis. Also, in a low percentage of pelvic or diaphragmatic cases, diaphragmatic fenestrations isolated or associated with the endometrial focus have been observed and diagnosed [8].

The theory of Sampson et al. [9], proposed to explain the relationship between these two phenomena, is that the retrograde menstrual bleeding that appears with columnar cells wrapped by a stromal with decidual reaction, causes ectopic implants of endometriosis, compatible with the appearance of collections of pleural fluid in the Diaphragmatic right side for physiological reasons of effusion and movement of peritoneal fluids. In addition, the most frequent extrapelvic location of endometriosis is the respiratory system [10].

Generally, pulmonary symptoms and cyclic occurrence are sufficient for the diagnosis of pulmonary endometriosis, and biopsy is not usually mandatory. However, intrathoracic lesions have been described during surgery, in which the diaphragm has been identified and classified according to criteria of the American Society of Reproductive Medicine (Figure 4), which is important because its knowledge, together with the correlation of the histopathological findings, allow a more accurate diagnosis of the types of disease [11]. In addition, patients with abdominal endometriosis and thoracic implants show predominantly posterior classic sentinel lesions, which cannot be easily seen by the umbilical port of laparoscopic surgery, thus reinforcing the recommendation for meticulous examination of the diaphragm at that level given the high Risk of secondary pneumothorax and recurrence [12]. However, Muller and Nelems [2] performed a review, in which they determined that recurrent catamenial pneumothorax can occur without thoracic endometriosis, due to the passage of air from the genital tract to the peritoneum and thence to the chest, also involving some cases of congenital diaphragmatic defects. Regarding treatment, multiple therapies have been described to allow definitive control of the disease. These should be performed
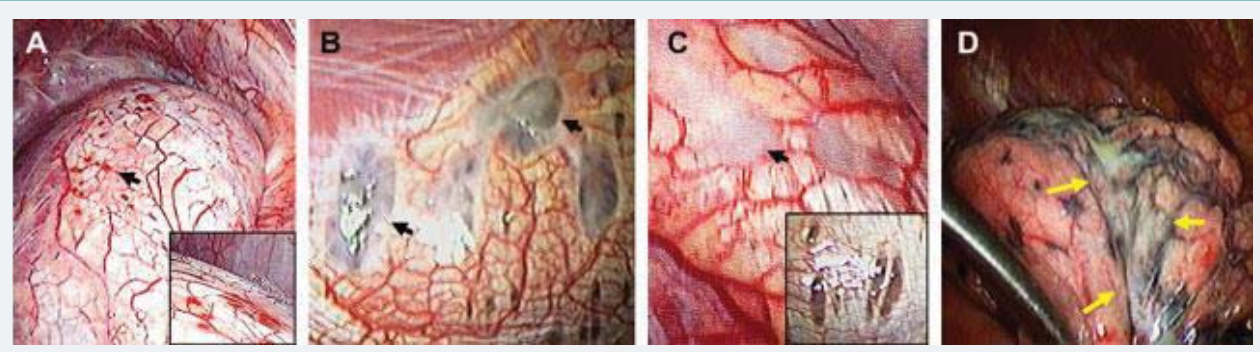

Figure 4: The American Society of Reproductive Medicine classifies the diaphragmatic lesions found in videothoracoscopic surgery according to its macroscopic appearance in: Rojas (A), black (B), white (C) and cicatricial lesions of the visceral pleural surface of the lung D). Image taken from Kumakiri J, Kumakiri Y, Miyamoto H, Kikuchi I, Arakawa A, Kitade M, et al. Gynecologic Evaluation of Catamenial Pneumothorax Associated with Endometriosis. J Minim Invasive Gynecol. 2010; 17 (5): 596 (8). 
individually by assessing the patient's age, desire for fertility, recurrence, and quality of life with symptoms [2]. Therefore, if the patient wishes to preserve her fertility, hormone suppression therapy has been consolidated as the best option, in which the analogues of gonadotropin hormone through the rupture of ovarian steroidogenesis, induce the resolution of endometriosis (Pulmonary or pelvic) [13] and decreased recurrence. Therefore, we emphasize that the importance of multidisciplinary management among the gynecologist, urologist, proctologist and general and thoracic surgeon has also demonstrated the depreciation in the recurrence rates of Disease, showing better postoperative results [11]. In summary, according to the literature found and our experience, the ideal management of thoracic endometriosis is apicectomy, placement of prosthetic material in the affected areas within the thorax and hormone therapy [12,14-17].

\section{Conclusion}

Although catamenial pneumothorax has been studied as an infrequent disease with multiple recurrences, each patient should be analyzed integrally and individually to correctly determine the aetiology of the pathology, using tools such as new classifications correlated to histological studies, which not only improve the Diagnosis, but, correct with the treatment of women with endometriosis. Currently, worldwide literature shows how the treatment of the combination of continuous hormonal therapy and a thorough review of the pleural, pulmonary and diaphragmatic alterations of endometriosis, provides a decrease in recurrence and improves prognosis of the disease.

\section{References}

1. MaurerER, Schaal JA, Mendez FL. Chronic recurring spontaneous pneumothorax due to endometriosis of the diaphragm. J Am Med Assoc.1958; 168: 2013-2014. Ref.: https://goo.gl/FiyN2b

2. Slabbynck $H$, Laureys $M$, Impens $N$, DeVroey $P$, Schandevyl W. Recurring catamenial pneumothorax treated with a Gn-RH analogue. Chest. 1991; 100: 851. Ref.: https://goo.gl/vJAPTL

3. Giudice LC, Kao LC. Endometriosis. Lancet. 2004; 364: 1789-1799. Ref.: https://goo.gl/HPPbZF

4. Azizad-Pinto $P, C l a r k e ~ D$. Thoracic endometriosis syndrome: case report and review of the literature. Perm J. 2014; 18: 61-65. Ref.: https://goo.gl/uChURZ

5. Alifano M, Trisolini R, Cancellieri A, Regnard JF. Thoracic endometriosis: Current knowledge. Ann Thorac Surg. 2006; 81: 761-769. Ref.: https://goo.gl/7WAFgy

6. Tettey M, Edwin F, Aniteye E, Seffah J, Tamatey M, et al. Thoracic endometriosis syndrome. West Afr J Med. 2013; 32: 302-306. Ref.: https://goo.gl/SSxuGb

7. Joseph J, Sahn SA. Thoracic endometriosis syndrome: New observations from an analysis of 110 cases. Am J Med. 1996; 100: 164-170. Ref.: https://goo.gl/iPucCc

8. Van Schil PE, Vercauteren SR, Vermeire PA, Nackaerts YH, Van Marck EA. Catamenial pneumothorax caused by thoracic endometriosis. Ann Thorac Surg. 1996; 62: 585-586. Ref.: https://goo.gl/iiS4Jw

9. Sampson JA. Metastatic or embolic endometriosis, due to the menstrual dissemination of endometrial tissue into the venous circulation. Am J Pathol. 1927; 3: 93-110. Ref.: https://goo.gl/8DmJEM

10. Joseph J, Reed CE, Sahn SA. Thoracic endometriosis: Recurrence following hysterectomy with bilateral salpingo-oophorectomy and successful treatment with talc pleurodesis. Chest. 1994; 106 : 1894-1896. Ref.: https://goo.gl/H98s4Y

11. Kumakiri J, Kumakiri Y, Miyamoto H, Kikuchi I, Arakawa A, et al. Gynecologic Evaluation of Catamenial Pneumothorax Associated with Endometriosis. J Minim Invasive Gynecol. 2010; 17: 593-599. Ref.: https://goo.gl/Jy2HKZ

12. Rousset-Jablonski C, Alifano M, Plu-Bureau G, Camilleri-Broet $S$, Rousset $P$, et al. Catamenia pneumothorax and endometriosis-related pneumothorax: Clinical features and risk factors. Hum Reprod. 2011; 26: 2322-2329. Ref.: https://goo.gl/SKjzSZ

13. L'huillier JP, Salat-Baroux J. [A patient with pulmonary endometriosis]. Rev Pneumol Clin. 2002; 58: 233-236. Ref.: https://goo.gl/1q9PnM 
14. Nezhat C, Main J, Paka C, Nezhat A, Beygui RE. Multidisciplinary Treatment for Thoracic and Abdominopelvic Endometriosis. JSLS. 2014; 18. Ref.: https://goo.gl/AkU1gA

15. Korom S, Canyurt H, Missbach A, Schneiter D, Kurrer MO, et al. Catamenial pneumothorax revisited: Clinical approach and systematic review of the literature. J Thorac Cardiovasc Surg. 2004. 128: 502508. Ref.: https://goo.gl/so5yfR

16. Vercellini $P$, Viganò $P$, Somigliana E, Fedele L. Endometriosis: pathogenesis and treatment. Nat Rev Endocrinol. 2014; 10: 261-275. Ref.: https://goo.gl/Y6HMBr

17. Nair SS, Nayar J. Thoracic Endometriosis Syndrome: A Veritable Pandora's Box. J Clin Diagn Res. 2016; 10. Ref.: https://goo.gl/ARgA3Q 